\title{
Retórica e argumentação na formação docente: uma experiência didática de proferição e avaliação do discurso
}

\author{
Jussara Maria Jurach \\ Professora adjunta da Universidade Estadual do Oeste do Paraná (UNIOESTE), Brasil. \\ jumariaju@yahoo.com.br
}

\section{Márcia Sipavicius Seide}

Professora associada da Universidade Estadual do Oeste do Paraná (UNIOESTE), Brasil. marciaseda4@hotmail.com

Resumo: A atuação do professor em sala de aula é permeada pela seleção de estratégias para construir conhecimento de modo atraente e agradável tanto para o docente quanto para os discentes, e a Retórica está diretamente ligada a esse processo. Com o objetivo de fomentar as discussões sobre essa relação entre Retórica e formação do docente, este artigo descreve os resultados obtidos por meio do uso de uma ferramenta didática denominada Proferição e Avaliação do Discurso (PAD), a qual foi desenvolvida para o trabalho na disciplina de Retórica, no curso de Letras da Universidade Estadual do Oeste do Paraná, Campus de Marechal Cândido Rondon. Os resultados obtidos permitem refletir sobre a percepção do professor como orador, o desenvolvimento da competência retórica, a adequação das formas de expressão da avaliação e a ética em sala de aula.

Palavras-chave: Retórica. Formação Docente. Ética em sala de aula. Ferramenta didática.

\begin{abstract}
The performance of the teacher in the classroom is permeated by the selection of strategies to build knowledge in an attractive and pleasant way for the teacher as well as for the students, and the Rethoric is directly associated to this process. Aiming at promote discussions about this relation between Rhetoric and teacher's training, this article describes the obtained results through the use of a didactic tool called Utterance and Discourse's Evaluation (UDE), which was carried out for the work of the Rethoric discipline in the Languages course of the Western Paraná State University at the Marechal Cândido Rondon Campus. The results obtained permit the reflection about the perception of the teacher as a speaker, the development of the rethoric competence, the suitability of the forms of evaluation expression and the ethics in the classroom.
\end{abstract}

Keywords: Rethoric. Teacher's Training. Ethics in the classroom. Didactic tool. 
Introdução

Em artigo publicado em 2010, a atividade de Proferição e Avaliação do Discurso (doravante PAD) foi descrita e fundamentada teoricamente (SEIDE, 2010). A principal motivação para a elaboração daquele artigo foi a necessidade de registro desta estratégia pedagógica, tendo em vista que a disciplina de Retórica, para a qual a atividade fora criada, estava sendo ofertada pela última vez, pois deixaria de ser ofertada na grade curricular do curso Curso de Licenciatura em Letras da Universidade Estadual do Oeste do Paraná do campus de Marechal Cândido Rondon. Seis anos depois, a disciplina recebeu outro nome - Retórica e Argumentação - e foi novamente introduzida no curso. Considerando esta mudança curricular, a PAD foi revisitada e utilizada, não pela professora que a criou, mas sim por outra docente que leu o artigo mencionado e ouviu um relato sobre como a PAD foi realizada nos anos anteriores.

Neste contexto, o objetivo deste artigo a descrição dos resultados obtidos pela utilização dessa ferramenta didática de modo a fornecer subsídios para a reflexão sobre a percepção do professor como orador, o desenvolvimento da competência retórica do docente, a adequação das formas de expressão da avaliação aos alunos e a ética em sala de aula.

Diferentemente dos anos em que a PAD foi primeiramente aplicada, de 2004 a 2010, no ano letivo de 2017 foi possível contar com a avaliação da atividade por parte dos alunos, uma vez que foi elaborado e aplicado um questionário avaliativo, o qual foi respondido por todos os alunos da disciplina. Tendo em vista que, no artigo de 2010, a avaliação discente contou com apenas dois relatos enviados por e-mail, o presente artigo preenche esta lacuna, pois analisa como os alunos avaliam a atividade de produção de avaliação do discurso. Além disso, o fato de essa ferramenta didática ter sido aplicada por outra docente a outros alunos com conhecimento e expectativas diferentes fornece dados com os quais se pode refletir sobre como ocorre a adaptação pedagógica de uma estratégia de ensino ao estilo do professor e dos alunos e ao momento sócio-histórico em que ambos se encontram.

Cumpre ressaltar que este esforço descritivo e interpretativo da prática docente que ensejou a última edição da PAD promoveu uma transformação salutar integradora das atividades de ensino e de pesquisa: num primeiro momento, se pesquisou para inovar a prática docente e, na sequência, o fazer 
$\mathrm{EI} D \bar{\alpha} \mathrm{A}$

Revista Eletrônica de Estudos Integrados em Discurso e Argumentação, llhéus, n. 17, jul./dez. 2018.

docente e o fazer discente foram eleitos como objeto de pesquisa para retroalimentação da teoria, concretizando o ciclo pesquisa-ensino-pesquisa.

Considerando o lapso de tempo transcorrido entre a última aplicação da PAD e sua retomada no novo projeto político pedagógico do curso que começou a ser implementado em 2017, foi feita uma breve revisão de literatura, a fim de verificar a existência de pesquisas anteriores que integrem argumentação, retórica, ensino e formação docente inicial, com inclusão da análise dos artigos e das resenhas já publicados na Revista Eletrônica de Estudos Integrados em Discurso e Argumentação a qual é apresentada na primeira seção deste artigo. Na segunda seção, a PAD é descrita; na terceira, seus objetivos pedagógicos são delineados; na quarta e última seção do artigo, os resultados obtidos são descritos e discutidos.

\section{Revisão de literatura e fundamentação teórica}

A busca em artigos publicados na própria revista sobre o assunto revelou uma quantidade considerável de estudos (SIEGEL, 2016 [1995]; BRETON, 2012; MARIANO, 2012; AZEVEDO, 2013; LEMES, 2013; SILVA, 2013; RODRIGUES, 2014; VENDRAMINI ZANELLA, 2015; GOULART 2016; RABATEL, 2016). Destas publicações relacionadas ao tema deste artigo, cinco estão mais próximas por complementarem ou dialogarem com a experiência pedagógica que se vai relatar a seguir.

Em artigo elaborado em 1995, traduzido e publicado em língua portuguesa em 2016, Siegel defende que um dos principais objetivos da educação é estimular a racionalidade dos alunos (SIEGEL, 2016). Ainda que não se discorde da importância do logos para o fazer retórico, a estratégia da PAD como recurso pedagógico para a formação docente inicial não desconsidera a dimensão pathética do discurso. Outra proposta de aplicação pedagógica da argumentação que também diverge da PAD é a experiência pedagógica realizada em 2010 com graduandos do $1^{\circ}$ ano do curso de Educação Especial e Logopedia em uma universidade em Barcelona, cuja descrição dos resultados da experiência permite perceber que a ênfase foi colocada exclusivamente na qualidade dos argumentos apresentados pelos alunos (CANO-ORTIZ, CASTELLÓ, 2011, p.271)

Mais atento à dimensão subjetiva e psicológica da argumentação, Breton utiliza a definição proposta por Perelman e Olbrechts-Tyteca, na qual também se baseia a PAD.Assim, coloca-se, em primeiro lugar, a influência decisiva do 
auditório, tendo em vista que a argumentação é o estudo das técnicas que possibilitam "provocar ou aumentar a adesão dos espíritos às teses que se Ihes apresentam ao assentimento" (PERELMAN; OLBRECHTS-TYTECA, 1996 p.4). Com base na proposta de Meyer (1993) de que, para ser exitoso numa argumentação, é necessária a negociação de distâncias, Breton conclui: “Argumentar é, enfim, uma fonte de desenvolvimento e de bem-estar pessoal que implica um desenvolvimento de memória, uma expansão mental, uma atenção aos outros" (BRETON, 2012, p. 119, grifos nossos). A conclusão de Breton vai ao encontro daquilo que se idealizou como resultado da aplicação da PAD na licenciatura.

Outra convergência com a PAD foi encontrada na fundamentação teórica utilizada por Loi e Lima. Para os autores, o fazer docente é visto como essencialmente pathético, como um conjunto de ações e dizeres que, muitas vezes, deve levar à solução de conflitos: "As paixões estão tão presentes nos conflitos escolares que, às vezes, perguntamo-nos se é possível ter um pouco de racionalidade nessa relação tão tensa entre professores e alunos" (LOI; LIMA, 2015, p. 100). Neste contexto, o professor "deve saber gerenciar razão e emoção" tendo em vista, inclusive, que "Dizer que o homem pode obter um grau zero de afetividade e um grau máximo de racionalidade é negar a existência de uma parte da natureza humana (LOI; LIMA, 2015, p. 100). De fato, os pressupostos desses autores convergem plenamente com os que fundamentaram a PAD desde a primeira vez em que foi aplicada em sala de aula (2004).

O estudo de Loi e Lima foi o único em que se considera o caráter pathético do fazer docente e da persuasão, tendo em vista que os demais tratam com exclusividade do logos da argumentação. Contudo, à medida que trazem reflexões preciosas sobre as contribuições do ensino do fazer argumentativo no contexto escolar, também auxiliam para um melhor entendimento da contribuição da PAD para a formação docente, conforme se explicará melhor na sequência.

Tratando, especificamente, do ensino da argumentação escrita, Mariano chama a atenção para o papel fundamental do professor para que o ensino seja realmente efetivado: não cabe "só ao livro didático, mas também aos professores aproveitar esse espaço para desenvolver nos alunos a capacidade de argumentar transformando-os em sujeitos críticos" (MARIANO, 2012, p. 104). 
Também focando o ensino de língua portuguesa nas escolas, Aquino e Lotti descrevem uma experiência pedagógica. No que diz respeito ao desenvolvimento da habilidade de argumentar oralmente, as pesquisadoras tecem questionamentos que remetem à formação docente inicial e continuada: "o que nós, professores, conhecemos sobre oralidade? Como aplicar esses conhecimentos em sala de aula de maneira ajustada? Do mesmo modo, o que os professores sabem sobre argumentação?" (AQUINO; LOTTI, 2015, p. 154-155).

Frente a estas questões, a utilização da PAD nos cursos de formação docente, inicial e continuada pode ser uma entre as respostas que se pode dar diante dos desafios descritos tanto por Mariano (2012) quanto por Aquino e Lotti (2015).

Se bem adote uma fundamentação teórica parcialmente distinta, a experiência educativa de Vendramini Zanella (2015) também converge com a PAD, por outros motivos: envolve alunos de Letras, focaliza a formação docente inicial, e o desenvolvimento do espírito crítico dos alunos é um de seus principais objetivos, haja vista que uma das metas a serem alcançadas era, precisamente, motivar os alunos a alcançarem "uma independência informada no lugar de dependência sem reflexão (modelos a serem imitados)" (VENDRAMINI ZANELLA, 2015, p. 99).

Assim, no contexto da PAD, com vista a este mesmo desiderato, ao invés de se fornecer aos alunos uma descrição minuciosa de como um discurso deveria ser proferido e avaliado, há a construção conjunta, elaborada com base na experiência vivida, dos critérios e dos parâmetros de avaliação.

A fim de relatar a experiência realizada no curso superior de Letras da Unioeste, apresenta-se, em primeiro lugar,a descrição da PAD a qual é analisada em seguida segundo objetivos pedagógicos, para, então, proceder à descrição da metodologia e dos procedimentos metodológicos empregados para a avaliação da PAD; por fim, os resultados obtidos são apresentados e discutidos com base em questões éticas sobre $o$ ensino na contemporaneidade.

\section{Descrição da PAD}

Enquanto, na edição de 2004, a PAD girou em torno de dois gêneros discursivos orais, a miniaula e o discurso propriamente dito, na de 2017 optouse pelo segundo gênero. Apresenta-se, a seguir, a PAD tal qual foi aplicada em 
2017, em uma turma do segundo ano da graduação em Letras, do período noturno, da Universidade Estadual do Oeste do Paraná, turma esta composta por 25 alunos, em sua maioria da faixa entre 19 e 25 anos.

A primeira fase da PAD ocorre no começo da disciplina. Nesta etapa, o professor motiva os alunos a recuperarem da memória como eram os professores que eles admiravam e a refletir sobre as qualidades deles e de suas aulas. Espera-se, com isto, que os alunos sejam levados a constatarem que o professor excelente é aquele que tem autoridade e consegue motivar os alunos a prestarem atenção, estudarem e realizarem as atividades pedidas e fazer de si mesmo "uma boa imagem". Tirando proveito dos relatos dos alunos, o professor os induz a chegar à conclusão de que a excelência do professor em sala de aula é fruto de um trabalho de convencimento e de persuasão que envolve, além do domínio do conteúdo (logos), o estabelecimento de confiança no docente (fides) e o domínio das paixões (pathos). Esta parte que antecede a PAD é fundamental para que os alunos percebam o papel retórico da atuação profissional da docência.

Esta recuperação de memória pode ser alcançada pedindo-lhes que escrevam uma descrição de um professor que eles admiram e consideram um professor ideal. Com base nestes relatos subjetivos, na aula seguinte, o professor apresenta algumas descrições para a turma e analisa as qualidades apontadas retoricamente (SEIDE, 2010).

Após a fase de preparação para a atividade, tem início a fase de organização da PAD. A fim de fomentar a manifestação dos alunos perante assuntos discutidos na sociedade, os temas a serem trabalhados nos discursos proferidos são sugeridos livremente pelos próprios discentes e, posteriormente, após uma sistematização em pares que representam posicionamentos opostos sobre os temas, estes são distribuídos. Nessa fase, o professor pede aos alunos para se organizarem em grupos de até cinco componentes de modo a formar de 08 a 10 grupos, segundo o número de alunos da turma. Cada grupo deve escolher quem será o orador, isto é, a pessoa escolhida será responsável pela proferição do discurso em sala, sendo que todos se encarregam da preparação, elaboração e avaliação dos discursos - o proferido pelo próprio grupo e o proferido pelos demais grupos. Para cada grupo, é dado um tema sobre o qual discursar e um posicionamento a ser defendido. 
Esta parte da organização segue o princípio clássico da retórica das falas divergentes, os dissoi logoi, pelo qual um mesmo assunto é visto sob pontos de vista antagônicos de modo que sobre um mesmo tema há um grupo que defende um ponto de vista e outro que o combate. Antes da distribuição dos assuntos, é preciso informar aos alunos sobre esta sistemática e esclarecer que "O discurso tem por objetivo conseguir a adesão dos espíritos, isto é, fazer com que a audiência compartilhe um ponto de vista sobre determinado assunto" (SEIDE, 2010, p. 258).

Os encaminhamentos que serão adotados para a avaliação do discurso também devem ser divulgados neste momento: para o grupo que se apresenta, é entregue um questionário de autoavaliação; para os demais grupos, outro questionário avaliativo é entregue. Após a proferição, há um tempo pré-determinado para os grupos se reunirem e anotarem as respostas. Em seguida, elas são apresentadas oralmente, começando-se pelo grupo que se apresentou.

Para se aumentar as chances de que o discurso a ser proferido seja preparado com antecedência e de modo minucioso, é preciso prever uma etapa de elaboração e avaliação inicial do discurso, para tanto, o grupo deve apresentar, quinze dias antes da proferição do discurso, ao professor, um texto escrito que contenha a planificação do discurso a ser proferido, na qual devem estar incluídos:

[...] o assunto, o objetivo, a escolha justificada das estratégias discursivas e dos materiais a serem utilizados, e uma descrição de como a apresentação começará, desenvolver-se-á e terminará, acompanhadas de explicações sobre quais são as expectativas do grupo. Ao final, devem constar as referências bibliográficas consultadas (SEIDE, 2010, p. 258).

De posse deste material escrito, o professor, uma semana antes da apresentação, deve entregar ao grupo sua avaliação comentada do planejamento feito, de modo que ao grupo seja possível ajustar e melhorar suas estratégias para o aperfeiçoamento do discurso a ser proferido.

Além da orientação oferecida pelo professor ao grupo, no processo didático que envolve a aplicação da ferramenta de PAD, não se pressupõe a elaboração de modelos prontos para serem seguidos pelos alunos. O que se propõe é que, no decorrer das proferições, as constatações aconteçam, via interação, e o conhecimento seja construído pela experiência. Nesse processo, paralelamente às apresentações quinzenais dos discursos, são trabalhados textos teóricos sobre o sistema retórico e são analisados discursos, a fim de 


\section{$\mathrm{EI} D \bar{\alpha} \mathrm{A}$}

proporcionar uma percepção crítica e consciente das estratégias retóricas utilizadas nas proferições realizadas pelos acadêmicos.

Vencida esta etapa preparatória, vem a fase de proferição e avaliação do discurso. Deve-se dedicar a esta fase uma aula geminada (aproximadamente 100 minutos de aula) para cada PAD, de modo que a primeira parte da aula seja usada para o discurso e a segunda para sua avaliação. Na parte de avaliação, o questionário respondido pelo grupo que proferiu o discurso deve motivá-lo a:

A partir das reações observadas pelo próprio orador e pelos demais componentes do grupo, o que fez a apresentação precisa perceber os pontos fortes e os pontos fracos da apresentação; avaliar em que medida a apresentação atingiu ou não os objetivos propostos e ser capaz de fazer uma autocrítica construtiva que inclua sugestões sobre o que pode ser feito futuramente em outras apresentações. Quanto aos demais grupos, se espera que consigam justificar as avaliações feitas apontando os fatores que levaram a ou impediram a adesão dos espíritos de modo eficaz, sincero e respeitoso e ser capaz de fazer uma autocrítica construtiva que inclua sugestões sobre o que pode ser feito futuramente em outras apresentação (SEIDE,2010, p. 259).

Proferidos os discursos e apresentadas oralmente as avaliações, os questionários preenchidos são entregues ao professor e tem início a finalização da atividade. Nesta etapa,

cabe ao docente avaliar as avaliações, sintetizar resultados e dar diretrizes para os próximos eventos [...]. Esta última parte é extremamente importante, já que é responsabilidade do professor fazer da experiência uma situação de ensino reflexiva e progressiva que consiga ir da prática à teoria e da teoria à prática (SEIDE, 2010, p. 259).

Na edição 2017 da PAD, além desta avaliação oral, logo após a avaliação dos alunos sobre o discurso proferido, houve a elaboração de um texto escrito pela professora no qual ela comunicava ao grupo que discursou a sua avaliação justificada.

Após essa breve explicação sobre em que consiste a PAD e como ela foi realizada no ano letivo de 2017, apresentam-se, a seguir, os objetivos pedagógicos da atividade e sua relação com a formação docente inicial.

\section{Os objetivos pedagógicos da PAD}

Por integrar a grade curricular de um curso de licenciatura em Letras, a PAD foi criada e tem sido aplicada tendo em vista o objetivo de promover algumas das habilidades necessárias ao fazer docente no Ensino Básico. Um 
$\mathrm{EI} \sqcap \mathrm{\alpha A}$

Revista Eletrônica de Estudos Integrados em Discurso e Argumentação, Ilhéus, n. 17, jul./dez. 2018

dos desafios da educação é a motivação dos alunos, os quais precisam ser convencidos e persuadidos a realizarem as tarefas necessárias ao processo de aprendizagem e permanecerem atentos durante as aulas. Outro desafio é a manutenção da disciplina e do processo de ensino ao longo da aula, para o que se faz necessário que o professor monitore as reações dos alunos. Este processo de monitoramento precisa ser feito de modo constante, preventivo e pró-ativo para que sejam feitas as mudanças necessárias para um bom desenvolvimento das aulas. Há também a necessidade de avaliação do processo de aprendizagem dos alunos. Além de elaborar, aplicar, corrigir e comunicar os instrumentos avaliativos, também é necessário saber comunicar os resultados da avaliação aos alunos.

Tendo em vista esta necessidade, o primeiro objetivo da PAD é propiciar que os alunos vivenciem esta necessidade de convencer e persuadir a audiência para a adesão dos espíritos, vivência que terão, diretamente, aqueles que forem escolhidos para serem os oradores do grupo e, indiretamente, aqueles que não sendo oradores, também participam da experiência. Em outras palavras, a experiência da PAD, aliada às aulas teóricas e às demais atividades previstas na disciplina, conduz os alunos a concluírem que o professor é um orador e que é necessário que eles se tornem bons oradores para serem bons professores.

O segundo objetivo da atividade é a exigência de avaliação da reação da audiência perante o discurso proferido, a qual serve de treino inicial para que, posteriormente, quando estiver atuando como professor em sala de aula, o licenciado possa monitorar a reação de seus alunos no decorrer das aulas que ministrará. Este treino se consegue nas repetidas ocasiões em que todos os grupos avaliam a proferição do discurso. No caso específico do grupo que profere o discurso, a avaliação deles é comparada com a de todos os outros, comparação que evidencia em que medida a autoavaliação converge com a avaliação da turma. Quanto maior a convergência, mais precisa é a autocrítica do grupo. Estar sujeito a tal comparação, na maioria das vezes, resulta no aperfeiçoamento da capacidade de autocrítica dos alunos.

O terceiro objetivo relaciona-se ao desenvolvimento da habilidade de comunicar resultados de avaliação, o que se consegue mediante as repetidas vezes nas quais os grupos precisam comunicar à turma como avaliaram o discurso dos colegas, avaliação que deve estar justificada retoricamente e ser feita de tal modo que não pareça ser uma crítica pessoal. 
4. Resultados obtidos: reflexões sobre os relatos dos alunos quanto às experiências de PAD

Como forma de avaliação dos resultados obtidos a partir das atividades de PAD, elaborou-se um questionário, o qual, após a última apresentação, foi respondido pela turma que cursou a disciplina de Argumentação e Retórica em 2017. Ao total, foram 24 questionários respondidos, cujas perguntas visaram à coleta de indícios referentes ao processo formativo dos acadêmicos e suas impressões sobre a ferramenta didática de PAD. As questões oferecidas aos alunos foram: Você gostou de participar das atividades de PAD? Por quê?; Você acredita que as atividades de PAD podem contribuir para a formação acadêmica? Por quê?; Conforme sua experiência, como as atividades de PAD influenciaram a sua formação docente inicial?; Como você percebeu a relação da turma com as atividades de PAD?

A análise das respostas dos alunos levou à percepção da existência de quatro tópicos principais relacionados aos objetivos da atividade e abordados pelos alunos sobre os resultados da PAD: (a) percepção do professor como orador; (b) desenvolvimento da competência retórica; (c) maneiras de expressão das avaliações; e (d) reflexão sobre a ética na docência e a necessidade de se desenvolver atitudes de tolerância perante as diferenças. Cada tópico será discutido detalhadamente, a seguir.

\section{a) A percepção do professor como orador}

Desde o início das aulas da disciplina Argumentação e Retórica, a formação docente foi posta em discussão, a fim de, justamente, deixar clara a relação intrínseca entre os textos teóricos estudados e a tarefa do professor orador. Muitos acadêmicos demonstraram surpresa ao perceber a relação entre a Retórica e a atuação docente, o que foi um elemento a mais para instigar os alunos a envolverem-se com a disciplina. Após a PAD, a maioria dos acadêmicos reconheceu o professor como orador e desenvolveu uma atitude crítica sobre a atuação docente como formadora de opinião, com se percebe no excerto a seguir:

(Resposta 1) - A PAD me mostrou a importância do encadeamento lógico da fala, além da necessidade de, em um discurso, saber o momento de instigar o emocional da minha plateia e de provar a minha credibilidade enquanto interlocutor. Estes ensinamentos valerão para minha formação docente, uma vez que o professor é um formador de discursos. 
Cabe destacar, conforme a resposta, que outro aspecto positivo da PAD sobre a formação docente é uma maior consciência sobre como o professor pode organizar o discurso e valer-se de argumentos que envolvem valores e emoções, como o ethos e o pathos, para promover o interesse dos alunos durante uma aula. Cumpre esclarecer que o logos também foi abordado. O encadeamento lógico da fala, traço destacado pela Retórica Clássica, foi exercitado a cada proferição do discurso, tanto pelo grupo que apresentava quanto pelos grupos que faziam parte do auditório.

Outro traço positivo observado no decorrer da aplicação da ferramenta de PAD é o aprendizado sobre a qualidade do conteúdo explorado e oferecido pelo orador em seu discurso, o que é obtido por meio de boas fontes de pesquisa, de seleção cuidadosa de informações e de métodos eficientes para tratar desses conteúdos conforme cada auditório, tarefas que fazem parte da invenção ${ }^{1}$ do discurso. A sequência estratégica do discurso e o cuidado com o conteúdo são destacados na resposta a seguir:

(Resposta 2) - Para minha formação docente inicial, a PAD possibilitou a prática de pensar em um discurso coerente e acessível ao público, o que é muito útil quando entramos em sala e precisamos ensinar conteúdos aos alunos, que são menos experientes que nós. Além disso, compreender a estrutura retórica pode facilitar a conquista dos alunos pelo conteúdo, por exemplo, com o exórdio e com o uso do pathos. Também acredito que uma grande influência da PAD é a de pensar no público para selecionar/organizar as ideias, pois como meu tema era polêmico, foi necessário excluir informações ou escolher a forma ideal de apresentá-las, o que também é útil para quando surgem situações delicadas em sala de aula.

A resposta do acadêmico evidencia que a atividade de PAD proporcionou-lhe a compreensão da relação entre os aspectos teóricos sobre argumentação e retórica e o trabalho do professor em sala de aula. Com esses resultados, acredita-se que as habilidades estimuladas pela PAD podem auxiliar no bem-estar docente, o qual está relacionado à percepção de controle sobre as ações.

Pela resposta, verificou-se que o acadêmico realizou o exercício de pensar o discurso conforme o auditório e que empreendeu um processo de seleção de informações para que o conteúdo do discurso fosse apresentado de modo atraente e adequado ao público. O fato de terem sido abordados

\footnotetext{
${ }^{1}$ Reboul (1998, p. 44) retoma as partes clássicas do discurso e as caracteriza como tarefas a serem realizadas para a execução de um discurso: "compreender o assunto e reunir todos os argumentos que possam servir (invenção); pô-los em ordem (disposição); redigir o discurso o melhor possível (elocução); finalmente, exercitar-se proferindo-o (ação).”.
} 
$\mathrm{EI} \square \mathrm{dA}$

Revista Eletrônica de Estudos Integrados em Discurso e Argumentação, Ilhéus, n. 17, jul./dez. 2018

temas polêmicos incentiva a reflexão sobre as estratégias utilizáveis para gerenciar as possíveis reações do auditório, habilidade também importante para o professor.

\section{b) O desenvolvimento da competência retórica}

O fato de este tópico tratar de "desenvolvimento" e não de "aquisição" da competência retórica mostra a adoção de um ponto de vista pedagógico que valoriza os conhecimentos prévios dos alunos. Essa concepção parte da percepção de que todos utilizam estratégias argumentativas e retóricas, mesmo que intuitivamente, nas relações cotidianas, inclusive as crianças em processo de aquisição de fala. Tal perspectiva também é evidenciada pela escolha metodológica de construção gradativa e coletiva do conhecimento a partir das próprias experiências discentes, pois não foram apresentados modelos prontos de discurso aos alunos. Cada grupo, na observação do outro, vai aperfeiçoando suas habilidades. Essas competências, desenvolvidas com certa autonomia e liberdade, permitem ao acadêmico a percepção da amplitude de fatores voltados à argumentação e à retórica no dia a dia, como se evidencia na resposta a seguir:

(Resposta 3) - Acredito que as atividades de PAD podem contribuir, visto que a retórica é igualmente importante em todas as esferas da sociedade, não somente na docência. Saber discursar, falar em público, se expressar claramente e coerentemente são algumas das atribuições que a PAD proporciona e que, sem dúvidas, contribuem para a formação acadêmica como um todo.

Além de permitirem a ponte com outros contextos sociais, os temas a serem trabalhados na PAD estimulam a criticidade, sobretudo porque permitem a criação de uma relação significativa entre os conteúdos teóricos e os assuntos em pauta na sociedade em geral. Assim, além de utilizar os conhecimentos da estrutura retórica, os acadêmicos precisam pensar criticamente nas várias posições argumentativas sobre os temas, a fim de empregar estratégias discursivas adequadas.

(Resposta 4) - As atividades de PAD auxiliam na formação acadêmica, pois cada grupo trabalhou junto para defender um tema polêmico, coletando dados, discutindo informações e opiniões entre os integrantes, além de pensar em uma sequência para a apresentação. Quanto a assistir às apresentações dos outros grupos e poder avaliar e discutir a 'performance' de quem estava apresentando foi algo interessante, pois nos fez pensar no que seria ideal em nossa apresentação e no que não seria tão interessante. 
Nessa resposta, também se pode perceber ainda que, ao avaliar o próprio discurso e o dos colegas, os acadêmicos também precisam desenvolver a criticidade para avaliar a apresentação dos outros grupos e para utilizar essa experiência ao organizar a própria apresentação. O tópico a seguir tratará justamente da relação da turma com o processo de avaliação.

\section{c) As maneiras de expressão das avaliações}

A maneira de expressar a avaliação envolve demonstração de atenção, compreensão e respeito sobre a produção de outrem e, por ser uma tarefa freqüente no cotidiano de qualquer professor convive, exige preparo. Uma avaliação que foge dos objetivos de construção do conhecimento e aperfeiçoamento pode afetar negativamente a experiência do aluno com o conteúdo trabalhado e comprometer todo o processo de aprendizado que deve ser propiciado no momento da avaliação.

A proposta avaliativa da PAD faz com que os acadêmicos se envolvam no processo de avaliação, tirando o foco apenas do professor. Por um lado, porque a autoavaliação permite que cada grupo discuta se atingiu os objetivos pretendidos e expresse essa percepção aos colegas. Por outro, porque, a partir de um roteiro pré-estabelecido e igual para todas as apresentações, cada grupo é convidado a discutir sobre o discurso apresentado pelos colegas e a expressar sua avaliação sobre a proferição do outro. Dessa forma, os acadêmicos precisam pensar em maneiras de dizer e em argumentos válidos para oferecer sua avaliação sobre o trabalho dos colegas, o que também é um processo construído pelas experiências de avaliação no decorrer das apresentações.

(Resposta 5) - À medida que as apresentações passavam, a turma soube diferenciar crítica pessoal de crítica à PAD. Nós também aprendemos a ver os dois lados do assunto e, muitas vezes, refletimos e hesitamos em tomar uma posição e não olhar o lado do outro, justamente porque aprendemos a respeitar.

A resposta do aluno representa o desafio de um aprendizado que acontece pela vivência com as situações. Inicialmente, alguns acadêmicos perceberam as críticas oferecidas nas avaliações feitas pelos grupos como crítica pessoal. No entanto, no decorrer das apresentações, a maioria dos alunos passou a ter um foco maior nos elementos retóricos presentes nos discursos proferidos e a expressar de modo mais respeitoso a avaliação e os posicionamentos de cada um, como se percebe na seguinte passagem: 
(Resposta 6): No geral, a relação foi de troca de opiniões, conselhos e observações necessários tanto para o aperfeiçoamento como para a manutenção de ideias, jeitos e formas defendidas ao longo das apresentações. Assim também houve uma troca de experiências entre os colegas, diálogos construtivos acerca de temas talvez mais polêmicos, demonstrando como cada um defende seu posicionamento, mas da mesma forma respeita o do próximo.

Apesar da maioria das percepções positivas, em alguns questionários, houve relatos sobre as dificuldades da turma durante a dinâmica de avaliação, justamente porque esta tarefa exige um processo de amadurecimento e de foco, como se verifica na resposta a seguir:

(Resposta 7) - Acho que quando chegava a hora da turma falar, a essência se perdia, dava para perceber falas pessoais, críticas voltadas à pessoa que apresentou, não sobre a apresentação em si. Em alguns momentos houve discussão.

Essas dificuldades relatadas exigem do professor da disciplina um constante trabalho de redirecionamento das avaliações para os aspectos argumentativos e retóricos, de orientação sobre os dizeres, sem fazer com que os alunos se sintam desencorajados a falar. Trata-se de um desafio pedagógico considerável, tendo em vista que os temas tratados em cada discurso são polêmicos e mobilizam as crenças, as emoções e as paixões do auditório. E é justamente por esse conjunto de situações que a PAD proporciona uma reflexão sobre a ética na docência e o desafio do respeito e da tolerância sobre as diferenças, fatores com os quais o professor deve saber lidar.

\section{d) Reflexão sobre a ética na docência e a tolerância sobre as diferenças}

Apesar da convivência em classe, algumas diferenças de posicionamentos entre os acadêmicos aparecem exatamente em momentos que estes são desafiados a interagir e a realmente assumir uma postura ativa no processo de construção do conhecimento. A atividade de PAD mobiliza os acadêmicos, professores em formação, para avaliarem o outro e a sua própria postura perante o diferente. Essa prática faz com que os alunos conheçam os posicionamentos dos colegas e, a fim de mediar conflitos, vivenciem a tolerância. Segundo Rebolo (2012, p. 45), "a construção de relações interpessoais positivas, pautadas no respeito mútuo, na colaboração e na transparência são os principais elementos do componente relacional do trabalho docente que o tornam potencial fonte do bem-estar dos 
professores". Percebe-se, assim, como é importante que as temáticas que envolvem as relações interpessoais no fazer docente sejam suficientemente abordadas nos cursos de Licenciatura.

Outro fator que propicia a ampliação dessas reflexões ocorre quando, na distribuição de temas para a PAD, a um grupo determinado, é atribuído um posicionamento sobre um tema que vai de encontro àquele que o grupo tinha anteriormente. Neste caso, o grupo precisa defender um posicionamento diferente daquele que inicialmente tinha, experiência que pode ensinar a ter um olhar diferenciado sobre a opinião alheia e a pensar no processo de argumentação e de contra-argumentação. Esse exercício de constituir um discurso que represente um ethos eficaz, embora o posicionamento do orador seja diferente, faz com que o horizonte de informações seja ampliado a partir de pesquisas que preparam o orador. Essa mediação de conflitos é uma das contribuições da PAD:

(Resposta 8) - A atividade nos permitiu ter voz para defender nossa real opinião ou a opinião que precisava ser defendida, além de nos fazer ouvir o outro e respeitar o que ele pensa. Por receber críticas em relação à proferição do discurso, tema, etc., aprendemos que nem sempre as críticas são referentes a nós, mas ao trabalho. Isso é essencial no ambiente acadêmico: se fazer respeitar e respeitar a opinião do outro.

Outra forma de enfrentar os desafios oferecidos pelo diferente aconteceu quando, a fim de evitar conflitos e constituir um discurso mais facilmente aceitável para a heterogeneidade de público, alguns grupos optaram por defender o posicionamento proposto de forma sutil, devido à dificuldade de alguns alunos para focalizar as avaliações e as críticas nas apresentações e não nos pontos de vista sobre os temas abordados nos discursos. O ensinamento que se pode oferecer sobre essas dificuldades com os pontos de vista é que as diferenças são inerentes aos processos humanos. Esta constatação vai ao encontro da reflexão de Breton (1999, p. 26-27) quando reconhece que "Chegar a um consenso sobre um mínimo de pontos de vista comuns implica um gigantesco trabalho de resultados sempre bastante modestos, e sempre prestes a recomeçar".

O fato é que, nesses enfrentamentos, a PAD permite que se reflita sobre a ética docente, o que é um aspecto complexo com o qual o professor convive. A ética docente envolve as atitudes do professor perante o diferente, como explica o acadêmico na resposta a seguir: 
(Resposta 9) - Como docente compreender a opinião dos outros é importante, por mais que dentro de sala o professor seja a "autoridade", não é só a opinião dele que deve prevalecer, embora não concorde com o assunto, como aconteceu em vários momentos da PAD, devemos respeitar a maneira de pensar de cada um.

Todas essas demonstrações de reflexão e de envolvimento dos acadêmicos com a PAD levam a considerar que essa ferramenta didática atinge os objetivos pretendidos e mobiliza os acadêmicos a se posicionarem criticamente.

\section{Considerações finais}

O trabalho desenvolvido com a ferramenta didática de PAD constitui um processo de ensino reflexivo e interativo, em que os alunos protagonizam as aulas e, com a mediação do professor, são levados a avaliar as atividades realizadas, a desenvolver senso crítico e a compreender o papel do professor como orador. Esta tarefa envolve desconstruções de pontos de vista e leva a momentos de autoconhecimento e de reflexão sobre a ética e o respeito às diferenças, exercício fundamental no cotidiano docente.

Além disso, o fato de ser um trabalho com retórica e argumentação realizado nos anos iniciais da graduação favorece um processo mais consciente de desenvolvimento da competência retórica ao longo do curso, do papel do professor orador e da percepção das formas de tolerância, não só na vivência dos acadêmicos no seu cotidiano na instituição de ensino superior como também quando têm contato com o campo de estágio. Por esses motivos, dentre outros, a atividade de PAD proporciona um processo didático em que as reflexões sobre a Retórica ultrapassam o conhecimento teórico e alcançam o eixo teórico-prático, tarefa desafiadora na formação docente.

\section{Referências}

AQUINO, Zilda Gaspar Oliveira de; LOTTI, Ana Luisa Feiteiro Cavalari. Argumentação e oralidade: a confluência de saberes entre ensino de língua e artes cênicas. EID\&A Revista Eletrônica de Estudos Integrados em Discurso e Argumentação, Ilhéus, n. 9, p. 153-174, dez.2015. 
$\mathrm{EI} \sqcap \mathrm{dA}$

Revista Eletrônica de Estudos Integrados em Discurso e Argumentação, Ilhéus, n. 17, jul./dez. 2018

AZEVEDO, Isabel Cristina Michelan de. Desenvolvimento de competências e capacidades de linguagem por meio da escrita de textos de opinião. EID\&A - Revista Eletrônica de Estudos Integrados em Discurso e Argumentação, Ilhéus, n.4, p. 35-47, jun.2013.

BRETON, Philippe. A manipulação da palavra. Tradução: Maria Stela Gonçalves. São Paulo: Edições Loyola, 1999.

BRETON, Philippe. Como convencer? Da comunicação argumentativa à manipulação. Tradução: Flávia Silvia Machado e Moisés Olímpio-Ferreira. EID\&A - Revista Eletrônica de Estudos Integrados em Discurso e Argumentação, Ilhéus, n.3, p.117-132, nov. 2012.

CANO-ORTIZ, Maribel; CASTELLÓ, Montserrat. Polifonia e dialogismo nas práticas argumentativas dos estudantes universitários em resposta a diferentes demandas. Tradução: Dayse Souza. In: Argumentação na escola: o conhecimento em construção. LEITÃO, Selma; DAMIANOVIC, Maria Cristina (org.). Campinas: Pontes, 2011. p. 251-274.

LEMES, Noemi. O texto dissertativo-argumentativo no livro didático: o discurso jornalístico silenciando a argumentação. EID\&A - Revista Eletrônica de Estudos Integrados em Discurso e Argumentação, Ilhéus, n.4, p. 89-101, jun.2013.

LOI, Marcia Acebedo; LIMA Anderson de Medeiros. "A retórica da sala de aula como sugestão para amenizar conflitos. In: A retórica do medo. 2. ed. MAGALHÃES, Ana N.; FERREIRA, Luiz Antonio; FIGUEIREDO, Maria L. (org). Franca: Cristal; São Paulo, Grupo ERA, 2015. p.89-104.

MEYER, Michel. Questions de Rhétorique: langage, raison et seduction. Paris Librairie Générale Française, 1993.

GOULART, Cecília Maria Aldigueri. Argumentação e aprendizagem da escrita na escola. EID\&A - Revista Eletrônica de Estudos Integrados em Discurso e Argumentação, llhéus, n. 12, p. 53-63, jul/dez.2016.

MARIANO, Márcia Regina Curado Pereira. O ensino da argumentação na Antiguidade e em um livro didático atual. EID\&A - Revista Eletrônica de Estudos Integrados em Discurso e Argumentação, llhéus, n.3, p.104-116, nov.2012.

PERELMAN, Chaïm; OLBRECHTS-TYTECA, Lucie. Tratado da argumentação. A Nova Retórica. Tradução: Maria Ermantina Galvão G. Pereira. São Paulo: Martins Fontes, 1996.

RABATEL, Alain. Os desafios das posturas enunciativas e de sua utilização em didática. Tradução: Weslin de Jesus Santos Castro. EID\&A - Revista Eletrônica de Estudos Integrados em Discurso e Argumentação, Ilhéus, n. 12, p. 191-233, jul/dez.2016.

REBOLO, Flavinês; TEIXEIRA, Leny Rodrigues Martins; PERRELLI, Maria Aparecida de Souza (org.). Docência em questão: discutindo trabalho e formação. Campinas: Mercado das Letras, 2012. 


\section{$\mathrm{EI} \square \mathrm{\alpha A}$}

Revista Eletrônica de Estudos Integrados em Discurso e Argumentação, Ilhéus, n. 17, jul./dez. 2018

REBOUL, Olivier. Introdução à Retórica. Tradução: Ivone Castilho Benedetti. São Paulo: Martins Fontes, 1998.

RODRIGUES, Maria Anunciada Nery. Revelações possíveis sobre o agir do professor em relatórios de estágio. EID\&A - Revista Eletrônica de Estudos Integrados em Discurso e Argumentação, Ilhéus, n. 7, p. 137-149, dez.2014.

SEIDE, Márcia Sipavicius. Atividades de Proferição e Avaliação do Discurso (PAD) como instrumento de formação de professores. Uniletras, Ponta Grossa, v. 32, n. 2, p. 255-268, jul./dez 2010.

SIEGEL, Harvey. Por que os educadores devem preocupar-se com argumentação? [1995]. Tradução: Gabriel Isola Lanzoni; Maria Gabriela Rodrigues de Castro; Sérgio Mikio Kobayashi; Winola Weiss Pires Cunha. EID\&A - Revista Eletrônica de Estudos Integrados em Discurso e Argumentação, Ilhéus, n. 11, p. 134-158, jan/jun, 2016.

SILVA, Viviane Netto. Reflexões em torno do discurso escolar: uma análise sobre o trabalho com a leitura em sala de aula. EID\&A - Revista Eletrônica de Estudos Integrados em Discurso e Argumentação, Ilhéus, n. 4, p. 102-111, jun.2013.

VENDRAMINI ZANELLA, Daniela Aparecida. A argumentação para o desenvolvimento de visão crítico-criativa de educadores. EID\&A - Revista Eletrônica de Estudos Integrados em Discurso e Argumentação, Ilhéus, n. 8, p. 98-110, jun.2015.

\section{Forma de citação sugerida}

JURACH, Jussara Maria; SEIDE, Márcia Sipavicius. Retórica e argumentação na formação docente: uma experiência didática de proferição e avaliação do discurso. EID\&A - Revista Eletrônica de Estudos Integrados em Discurso e Argumentação, Ilhéus, n. 17, p. 85-102, jul./dez.2018. DOI dx.doi.org/10.17648/eidea-17-2089. 